\title{
DOSSIÎ̂
}

\section{Policy community defensora de direitos e a transformação do Conselho Nacional de Assistência Social ${ }^{1}$}

\section{Resumo}

O artigo examina a ação estratégica de um ator coletivo, a policy community defensora da assistência social como direito dos cidadãos, a qual resultou não apenas na criação do Sistema Único de Assistência Social (SUAS), mas também na redefinição das funções do Conselho Nacional de Assistência Social (CNAS), ao final da década de 2000. Membros dessa community aproveitaram sucessivas janelas de oportunidades para apresentar aos decisores políticos propostas de solução para os problemas da extremada desigualdade social e pobreza, colocados no centro da agenda política e governamental desde o Governo Lula, iniciado em 2002. Uma dessas janelas de oportunidades abriu-se com a Operação Fariseu, em 2008, que expôs a existência de relações ilícitas entre conselheiros e entidades que recebiam certificação como beneficentes de assistência social e, portanto, vultosas isenções fiscais. A community teve sucesso em retirar do fórum a prerrogativa de certificar e controlar as atividades de entidades 'beneficentes', transferindo-a às burocracias governamentais das áreas de assistência social, saúde e educação. Dessa forma, o CNAS, uma organização intermediária neocorporativa criada pela Lei Orgânica da Assistência Social, consolidou o seu papel na

${ }^{1}$ Grande parte deste artigo foi publicada em inglês, conforme a seguinte referência bibliográfica: Brazil's National Council for Social Assistance and the policy community supporting social assistance as a right. In: Vaitsman, Jeni; Ribeiro, José M.; Lobato, Lenaura. (Org.). Policy Analysis in Brazil. 1ed. Bristol, UK: Polity Press, 2013, p. 135-148.

*Universidade Federal do Rio Grande do Sul (Brasil). 
intermediação de interesses entre os diversos atores societais e estatais visando viabilizar a implementação das políticas definidas no nível federal de gestão que resultaram na estruturação do SUAS.

Palavras-chave: Sociologia Política. Comunidade política. Assistência social.

\title{
Policy community advocating for social rights and the restructuring of the National Council of Social Assistance
}

\begin{abstract}
The article examines the strategic action of a collective actor, the policy community that advocates for social assistance as a right of citizens, which resulted not only in the creation of the Brazilian Unified Social Assistance System (SUAS - Sistema Único de Saúde)), but also got to redefine the functions of the National Council of Social Assistance (CNAS), by the end of 2000. Members of this community took successive windows of opportunity to present to policy makers proposals for tackling problems of extreme social inequality and poverty, which were central to the political and governmental agenda as of Lula Government started in 2002. One of these windows of opportunity opened up with Operação Fariseu in 2008, which exposed the existence of illicit relations between council's board members and organizations that acquired certification as welfare charities, thus receiving significant tax exemptions. The policy community succeeded in revoking the Council's prerogative to certify and control the activities of 'charities', transferring it to governmental departments in the areas of welfare, health and education. Thus, CNAS, a neo-corporative intermediary organization created by the Organic Law of Social Assistance, consolidated its role as mediator of interests between societal and state actors aiming to facilitate the implementation of the national policies that resulted in the structuring of SUAS.
\end{abstract}

Keywords: Political Sociology. Political community. Social assistance. 
Sociologias, Porto Alegre, ano 17, oo 38, jan/abr 2015, p. 122-154

Introdução

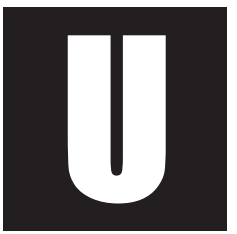

ma das principais peculiaridades da sociologia política é que, ao tratar de dois pressupostos fundamentais da Sociologia - ação e ordem, segundo Alexander (1982) - enfatiza a dimensão relacionada à capacidade das pessoas de alcançarem objetivos simbólicos, intencionalmente perseguidos, em situações simbolicamente definidas (Lehman, 2010). Essas pessoas são vistas como atores que não seguem apenas scripts impostos culturalmente, sobre os quais frequentemente não têm consciência, mas são agentes cuja ação tem a intenção de atingir objetivos, sejam eles relacionados a mudanças na ordem ou à sua manutenção. Por isso, para a sociologia política, a noção de poder é central. Pelo menos para aqueles que se filiam à tradição weberiana, ela denota a capacidade de indivíduos e grupos intencionalmente compelirem outros a fazer aquilo que, de outro modo, não fariam. Sem desconsiderar a importância dos imperativos culturais, tanto normativos como cognitivos (Campbell, 2002), e dos constrangimentos institucionais, este estudo examina a ação estratégica, intencional, de um ator coletivo, a policy community defensora da assistência social como direito dos cidadãos, que resultou, para além da criação de um sistema nacional de assistência social, também na redefinição das funções do Conselho Nacional de Assistência Social (CNAS), ao final da década de 2000. O foco da pesquisa empírica que fundamenta este artigo recai sobre essa mudança nas funções do Conselho.

A assistência social se destaca dentre as demais políticas setoriais, porque, nos anos 2000, deixou de agregar um conjunto de ações relativamente desordenadas promovidas por primeiras-damas e por pessoas ou organizações 'caridosas' - no Brasil denominadas filantrópicas - para tornar-se uma das mais importantes áreas de política pública no país (Vaitsman et al., 
2009). Nos anos 1990, passou ser coordenada por ministério específico e, embora tenha perdido a condição de pasta ministerial autônoma entre 1994 e 2002, retomou-a em 2003. Mesmo que o Ministério da Assistência Social tenha sido extinto com a criação do Ministério do Desenvolvimento Social e Combate à Fome (MDS), a importância da área, integrada ao novo órgão, não se reduziu. Ao contrário, ampliou-se (Brasil, 2011). Isso pode ser atestado pelo crescimento vertiginoso do gasto público federal com assistência social. Entre 1995 e 2010, foi a área social que mais se expandiu se tomarmos como indicador o gasto social federal, crescendo 307\% (Castro et al., 2012). No período, o percentual do Produto Interno Bruto brasileiro a ela destinado passou de 0,08\%, em 1995, para 0,75\%, em 2004, ano da criação do MDS, e 1,07\%, em 2010 (Castro et al., 2012).

O arcabouço institucional normativo que propiciou a estruturação da área encontra suas origens na Constituição de 1988 (Brasil, 1988). Embora a carta constitucional não tenha criado um sistema assistência social, ela garantiu o direito dos desamparados à assistência, à 'descentralização político-administrativa' e à 'participação da população' (Brasil, 1988, art. 204). Depois de 1993, a legislação complementar à Constituição e medidas administrativas de âmbito federal instituíram: fóruns participativos - conselhos e conferências - nos níveis federal, estadual e municipal de gestão; fundos nacional, estaduais e municipais destinados exclusivamente ao financiamento da assistência; mecanismos de transferência de recursos financeiros da esfera federal para a estadual e municipal; comissões intergestores de coordenação federativa; os municípios como os principais responsáveis pela implementação das políticas nos territórios sob sua jurisdição. O ponto culminante do processo foi a edição de duas normas operacionais básicas: a primeira, em 2004, que criou o Sistema Único de Assistência Social (SUAS) (Brasil, 2004), e a segunda, em 2005, que normatizou o novo sistema (Brasil, 2005). Acelerava-se um processo de mudança que se iniciara 
Sociologias, Porto Alegre, ano 17, no 38, jan/abr 2015, p. 122-154

na década de 1990, quando da edição das normas operacionais básicas de 1997 e 1998, que estabeleceram as características básicas e os mecanismos de financiamento, gestão federativa e regulação do sistema que viria a ser criado formalmente na década seguinte.

Além do arcabouço normativo, outras características institucionais definem um setor de políticas públicas e afetam a dinâmica de funcionamento de um fórum participativo e o papel que ele desempenha. Há que considerar a natureza dos serviços que são oferecidos; a dimensão dos recursos financeiros públicos e privados mobilizados; o grau de desenvolvimento das capacidades administrativas governamentais; quem são os beneficiários da política em questão e os tipos de grupos de interesse e policy communities envolvidas na arena política setorial. A assistência social é financiada basicamente por recursos públicos federais (Brasil, 2007) e oferece serviços e bens sociais por meio de uma rede de prestadores públicos, filantrópicos e privados. As capacidades administrativas governamentais em um sistema de assistência social constituído recentemente, que teve pela primeira vez status ministerial na década de 1990, são ainda pouco desenvolvidas, ainda mais se tendo em consideração o tamanho do desafio proposto pelo SUAS de oferecer serviços e benefícios assistenciais em todos os municípios da federação brasileira. Mesmo assim, impressiona o fato de, em 2009, existirem conselhos municipais de assistência social em 99,3\% dos municípios e a quase totalidade (99,8\%) ter algum tipo de estrutura administrativa municipal responsável pelas questões da área. Porém, no mesmo ano, apenas 70\% deles tinham secretaria que trabalhasse exclusivamente com a assistência social, em um quarto dos municípios, a política era conduzida pela primeira-dama e, em 53,6\% deles, o dirigente da área não tinha curso superior (IBGE, 2009).

A assistência social é destinada aos desamparados. A questão da imagem pública da política (Ingram et al., 2007) está relacionada a sua natureza 
focalizada. Para aqueles de inclinação ideológica liberal, apenas alguns crianças ou pessoas com deficiências, por exemplo - merecem amparo. Os demais deveriam garantir sua sobrevivência no mercado. Associada a essa concepção está a perspectiva - a qual remonta aos alvores das políticas sociais em países europeus ao final do século XIX e início do século XX que atribuía às organizações voluntárias caritativas função preponderante na provisão de amparo aos necessitados (Alcock, 2003). No Brasil, organizações vinculadas às igrejas cristãs, marcadamente a católica, foram as principais responsáveis por este tipo de atenção assistencial (Menezes, 2010). Para outros, como é o caso dos idealizadores da proposta de construção do SUAS no Brasil, têm direito ao amparo da assistência social todos os cidadãos que se encontram abaixo de certos patamares de renda e de acesso a serviços e bens, independentemente das razões pelas quais se encontrem em tal situação. O crescimento da importância relativa da área, na última década, reflete não apenas as mudanças instituídas pela Constituição Federal de 1988, mas também as ações estratégicas desenvolvidas por uma policy community que defendia tal concepção, cujos membros, a partir de 2004, assumiram a direção da política federal na área de assistência social.

Em 1994, ao início do contexto do processo de estruturação da assistência social como política pública, foi instalado o novo CNAS. Seu antecedente histórico era o Conselho Nacional de Serviço Social, formado por 'notáveis', que fora criado em 1938 (Raichelis, 2000). O CNAS, assim como fóruns similares de outras áreas, é uma organização intermediária neocorporativa criada pelo Estado brasileiro, que está no topo de uma cadeia de conselhos estaduais e municipais e de processos conferencistas periódicos. Ao longo da década de 2000, dele emanaram Resoluções fundamentais para a normatização do sistema que se estruturava. Em 2009, graças à aprovação da Lei 12.101 (Brasil, 2009), o Conselho perdeu a função que exercera tradicionalmente desde a criação do Conselho Nacional de Serviço Social: certificar 
entidades como beneficentes de assistência social, garantindo-lhes isenções fiscais. Completava-se, desse modo a transição do CNAS para um novo papel institucional no âmbito do SUAS, recém constituído.

A pesquisa que deu origem a este artigo trata desse cenário conturbado $^{2}$. O foco da investigação recai sobre o ano de 2010, embora não se restrinja a ele. Nesse ano, a mudança provocada pela Lei 12.101 levou o Conselho a refletir sobre seu papel institucional. Argumenta-se aqui que as mudanças enfrentadas pelo o CNAS no período foram, em grande parte, o resultado da ação da policy community defensora da assistência social como direito.

O artigo está estruturado em três seções. Na primeira, são discutidos os conceitos de organização neocorporativa intermediária e de policy community para entender o papel desempenhado pelo CNAS no contexto da estruturação do SUAS no país, graças, ao menos em parte, à ação de uma community que defendia a assistência social como um direito de cidadania. Na segunda, são analisados os atores participantes e modo de funcionamento do Conselho. Na terceira, é examinada a ação dessa community reformista e a mudança no papel institucional do CNAS.

\section{CNAS como uma organização intermediária neocorporativa e ação de policy communities}

O CNAS é uma "organização intermediária" neocorporativa, no sentido atribuído ao termo por Streeck e Kenworthy (2005, p. 15-17). É uma

\footnotetext{
${ }^{2}$ Foram analisadas: leis e portarias ministeriais pertinentes; resoluções e outros documentos do próprio Conselho; informações disponíveis nos sites do Conselho e do Ministério do Desenvolvimento Social e Combate à Fome (MDS) e atas das 11 reuniões plenárias do CNAS. Foram ainda utilizadas no estudo transcrições de entrevistas com dois conselheiros muito atuantes no Conselho, um representante da sociedade civil e outro do governo federal, e dois gestores do MDS e um gestor estadual, os três últimos muito envolvidos no processo de construção do SUAS.
} 
instância não só reconhecida como também, no caso, embrionada por iniciativa dos governos, os quais exercem sobre ela forte influência no sentido de estabelecer a intermediação de interesses de diversos atores societais (Côrtes e Gugliano, 2010, p. 52). Os fóruns nacionais, constituídos 'a partir de cima', integram o nível superior de um grande arranjo interorganizacional de organizações intermediárias, que interagem com organizações intermediárias pertencentes ao nível inferior, formadas a partir de baixo. ${ }^{3}$ A participação de representantes de diferentes grupos de interesses não significa atribuição de "licenciamento" estatal às organizações representadas, tal como ocorre no corporativismo estatal, mas, sem dúvida, tem o caráter de "reconhecimento" e, portanto, de legitimação desses representantes frente aos membros das respectivas associações, como ocorre no neocorporativismo ou corporativismo societal. Desse modo, os representantes que ali participam são vistos como líderes capazes de influenciar políticas. Mais do que isso, muitas vezes, os representantes podem comprometer-se em favorecer o cumprimento de decisões ou até mesmo podem tornar-se responsáveis, junto com suas organizações, pela execução das políticas (Côrtes e Gugliano, 2010, p. 52). ${ }^{4}$

Boa parte dos analistas de políticas públicas toma como referência o modelo de Kingdon (1995) que trata das instituições e dinâmicas políticas dos Estados Unidos. Esse sistema é altamente pluralista, com uma infinidade de 'pessoas importantes' no legislativo e na sociedade influindo na formação da agenda governamental, carente de uma clara hierarquia entre os diversos atores. Em sistemas com dominância do executivo conjugada à predominância do partido do governo (maioria ou coalizão), é

\footnotetext{
${ }^{3}$ Ver a análise de Lamping, A. J.; Raab, J; Kenis, P. (2010) para o sistema de saúde holandês. ${ }^{4}$ Sobre o tema, sugerimos consultar também o conceito de "corporativismo de bem-estar" (welfare corporatism), empregado por Mishra (1984) e Williamson (1989), a partir do qual a ênfase do debate recaí sobre os profissionais e outros produtores de serviços e bens no âmbito do Estado de Bem Estar Social.
} 
possível que um grupo, em torno do executivo central, tenha um poder excepcional na definição de quais questões serão objeto de decisão governamental. O grupo central do poder executivo tem também poderosa influência, senão o controle sobre o processo no qual as alternativas de solução para problemas colocados na agenda governamental são discutidas e escolhidas (Page, 2006, p. 209).

Embora a literatura que aborda a questão da 'dominância do executivo' frequentemente se refira à distinção entre o processo decisório dos Estados Unidos e de países europeus (Heclo, 1978; Page, 2006), a advertência também é cabível na análise do caso brasileiro. O caráter 'organicamente estatista' (Stepan, 1985) das relações entre Estado e sociedade no Brasil, aproxima mais o sistema político do país ao modelo de 'dominância do executivo' (Figueiredo et al., 1999). Desde os anos 1930, o Estado desenvolvimentista brasileiro participou ativamente na conformação da sociedade civil do país por meio da imposição de arranjos corporativos (Diniz; 1992; O'Donnell,1978; Rodrigues, 1990; Schmitter, 1971). Nos anos 1980, como resultado das políticas do regime militar, grande poder discricionário estava concentrado nas mãos do governo central, que se tornara virtualmente responsável por todas as políticas públicas. O processo de democratização em curso era impulsionado pelo intenso engajamento político de sindicatos de trabalhadores, organizados em moldes corporativistas (Nogueira, 1999; Pichler, 2005; Stepan, 1985). Havia também associações de moradores, ambientalistas, feministas, entre outros, além de movimentos sociais com estrutura organizativa relativamente difusa. Nos anos 1990, o Estado brasileiro preservou certas característica corporativistas em seu sistema de relações de trabalho (Córdova, 1989; Nogueira, 1999; Pichler, 2005), renunciando, porém, aos traços autoritários originais. Ele ainda estruturou a governança por meio da criação de organizações intermediárias neocorporativas: notadamente os conselhos 
Sociologias, Porto Alegre, ano 17, no 38, jan/abr 2015, p. 122-154

de políticas públicas. Formadas pelo próprio Estado, essas organizações se relacionam intensamente com organizações intermediárias societais, que congregam representantes de interesses empresariais, de entidades filantrópicas, sindicais e de profissionais e de associações da sociedade civil.

Em contextos de países em desenvolvimento, com estruturas socioeconômicas acentuadamente desiguais, formas de representação de interesse, tais como as neocorporativas, podem abrir o espaço decisório para grupos sociais sem capacidade de se fazer representar adequadamente na esfera pluralista (Santos, 2001). Pode-se acrescer, ainda, que o que viabiliza a participação no processo decisório é a proximidade dessas organizações intermediárias neocorporativas aos membros políticos do núcleo central de gestão. Se, por um lado, criam-se canais de influência societal sobre os decisores governamentais, por outro, estes podem comprometer representantes de organizações societais com a implementação de medidas decididas nesses fóruns. Esta é uma das principais razões da importância assumida por organizações intermediárias neocorporativas, como os conselhos de políticas públicas, durante a implantação da política de assistência social nos anos 2000. No entanto, a percepção de que uma instituição neocorporativa poderia favorecer a implementação de determinadas políticas e a decisão de ali atuar dependeram da existência de uma articulação de atores societais e estatais que compartilhavam uma determinada visão sobre os resultados desejáveis da política.

As decisões políticas no setor público dependem, cada vez mais, de um aparato estatal profissionalizado que formula políticas setoriais substantivas. Nesse contexto, constituem-se policy communities, a partir de relações estabelecidas entre atores no interior de redes existentes em áreas específicas de políticas públicas (Heclo, 1978). ${ }^{5}$ As redes envolvem uma

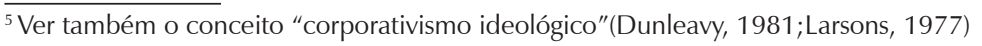


Sociologias, Porto Alegre, ano 17, no 38, jan/abr 2015, p. 122-154

grande variedade de atores, movendo-se para dentro e para fora das arenas políticas, com visões diferentes sobre quais deveriam ser os resultados das políticas. Elas pressupõem a existência de uma grande variedade de centros de decisão política (Smith, 1991). A noção de policy community, em contraste, refere-se a um número limitado e relativamente estável de membros que dividem os mesmos valores e visão sobre quais devem ser os resultados da política setorial. As decisões são tomadas dentro dessas communities, em processos fechados para outras comunidades e para o público em geral (Rhodes, 1986). Policy communities participam das redes de políticas, tentando afetar processos decisórios que se tornaram muito segmentados, na medida em que as políticas são elaboradas por uma miríade de organizações interconectadas e interpenetradas (Jordan \& Richardson, 1979).

As noções de policy community e rede de política (Heclo, 1978; Jordan \& Richardson, 1979; Rhodes, 1986) buscam entender como se processam as decisões nas diversas áreas de políticas públicas e nos centros decisórios dos governos. Elas podem ser denominadas como triângulos de ferro, nichos temáticos, subsistemas políticos, redes temáticas, advocacy coalitions, mas "qualquer que seja a denominação adotada, ela se refere a uma comunidade de especialistas operando fora do processo político visível, em contextos nos quais a maior parte das questões de cada política setorial específica é tratada no interior de uma comunidade de experts" (True; Jones \& Baumgartner, 2007, p. 157-158). Um grupo de experts, integrantes de uma community, ao tornar-se decisor político, age no sentido de escolher as alternativas de solução para os problemas que se apresentarem na agenda governamental que sejam as mais adequadas aos seus valores e visão sobre os resultados desejáveis da política. Age de forma estratégica e constrói alianças com atores societais e governamentais para a consecução de seus objetivos. Organizações neocorporativas intermediárias podem se constituir como um espaço de articulação polí- 
tica privilegiado para o desenvolvimento dessa estratégia, como ocorreu com o CNAS nos anos 2000.

Mesmo reconhecendo a importância das policy communities, as distinções entre Estado, sociedade civil e mercado também apresentam valor heurístico para análise de como tais articulações foram realizadas no CNAS. O conceito de atores estatais abarca indivíduos que ocupam cargos de direção em órgãos do Executivo ou em organizações governamentais. Eles são representantes da gestão em assistência social de nível federal, estadual e municipal ou de órgãos públicos do executivo que não atuam diretamente na área.

O conceito de atores societais é muito amplo para expressar diferenças essenciais entre dois tipos de atores: os sociais e os de mercado. Enquanto os primeiros estão associados ao conceito de sociedade civil, os segundos estão relacionados com a noção de economia de mercado. A sociedade civil e seus atores são diferentes do Estado e do mercado, e de seus atores. Os atores estatais e de mercado são compelidos a agir em ambientes regidos pelo poder e pelo dinheiro, enquanto o mesmo não acontece com os atores sociais (Cohen, 2003). Atores sociais não visam tomar o poder do Estado ou organizar a produção, mas, sim, exercer influência por meio da participação em associações e movimentos democráticos (Cohen, 2003, p. 427). Atores de mercado buscam controlar e administrar a produção, maximizar seus lucros no ambiente de trocas mercantis. $\mathrm{O}$ sentido principal as ações políticas dos decisores econômicos é guiado por imperativos da produtividade e do lucro. Neste estudo os atores sociais foram classificados nas seguintes categorias: profissionais e trabalhadores da área; trabalhadores, não especificamente da área; associações de pessoas em situação de vulnerabilidade social; entidades de pessoas com patologias ou deficiências; e entidades religiosas. Levando em conta os mesmos critérios, os atores de mercado são os prestadores privados de 
Sociologias, Porto Alegre, ano 17, oo 38, jan/abr 2015, p. 122-154

serviços na área, envolvidos na provisão de serviços e bens sociais. Embora os provedores de serviços e bens sociais, na área, sejam juridicamente classificados como filantrópicos, foram aqui tratados como privados se as organizações das quais os conselheiros eram provenientes atuavam no mercado de serviços educacionais, de saúde ou de assistência social.

Analisa-se, a seguir, o funcionamento do Conselho Nacional de Assistência Social, uma organização neocorporativista intermediária que, no ano de 2010, passou por profundas transformações. Ao mesmo tempo em que perdeu sua tradicional função cartorial de atestar entidades como 'beneficentes', consolidou o seu papel de órgão essencial para a construção das normas que guiaram a institucionalização do SUAS no país.

\section{Conselho Nacional de Assistência Social (CNAS): a predominância de representantes do governo federal}

Em 2010, o Conselho era formado por plenário, comissões permanentes, comissões temporárias, grupos de trabalho, secretaria executiva e um núcleo dirigente, chamado Presidência Ampliada (Brasil, 2009a; 2010a). ${ }^{6}$ O CNAS dispunha ainda de três câmaras de julgamento, que eram remanescentes de sua função pretérita a novembro de 2009 (Brasil, 2009a), quando ainda concedia Certificados de Entidades Beneficentes de Assistência Social (CEBAS).

A instância mais importante era o plenário, integrado por 18 membros titulares, cada um com um suplente (Quadros 1). A ele cabia analisar e deliberar sobre propostas de ações e políticas e produzir Resoluções. Havia ainda as comissões permanentes - de política, de conselhos, de financiamento e de normas -, os grupos de trabalho e comissões tem-

${ }^{6} \mathrm{O}$ CNAS localizava-se em um complexo de salas de apoio de reuniões no Anexo A, do Ministério do Trabalho. 
porárias compostas e coordenadas por conselheiros. Sua finalidade era discutir de forma aprofundada os assuntos específicos de que tratavam e subsidiar com suas análises as decisões do plenário. À secretaria executiva, diretamente subordinada à Presidência do Conselho e funcionalmente vinculada ao MDS, cabia a responsabilidade de administrar a estrutura de apoio aos trabalhos do fórum. Coordenava também a tramitação dos processos remanescentes referentes à concessão do CEBAS. ${ }^{7} \mathrm{O}$ núcleo dirigente - Presidência Ampliada - era eleito pelo plenário dentre os conseIheiros. A Presidência concentrava boa parte das atribuições de direção e representação no Conselho. As reuniões plenárias do CNAS, coordenadas pela Presidência, eram mensais, ocorrendo em dias consecutivos. Em geral duravam dois ou três dias, nos turnos da manhã e da tarde. As pautas eram elaboradas com antecedência pelo núcleo dirigente.

Existia uma sobrerrepresentação governamental originária na composição do plenário do CNAS, fruto da legislação que estabeleceu a obrigatoriedade de paridade entre os representantes da 'sociedade civil' e do 'governo' (Brasil, 1993). O grupo 'governo' abrangia representantes das esferas federal, estadual e municipal de gestão, enquanto os conselheiros provenientes de organizações de provedores, de beneficiários de serviços e bens sociais e de profissionais e trabalhadores compunham o segmento 'sociedade civil'. Como pode ser observado no Quadro 1, em 2010, dos nove representantes governamentais, sete provinham de órgãos federais, ou seja, sozinhos perfaziam 39\% dos integrantes do Conselho.

${ }^{7}$ Em 2010, havia ainda um passivo de 2.781 requerimentos e documentos relativos a certificados concedidos para serem processados (Brasil, 2010b). 
Sociologias, Porto Alegre, ano 17, no 38, jan/abr 2015, p. 122-154

Quadro 1. Composição do Conselho Nacional de Assistência Social por representantes estatais e societais - 2010

\begin{tabular}{|c|c|c|c|}
\hline 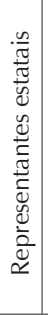 & Governamentais & & $\begin{array}{l}\text { - Ministério do Desenvolvimento } \\
\text { Social e Combate à Fome (quatro } \\
\text { representantes) } \\
\text { - Ministério da Previdência Social } \\
\text { - Ministério do Planejamento, Orça- } \\
\text { mento e Gestão } \\
\text { - Ministério da Educação } \\
\text { - Fórum Nacional de Secretários de } \\
\text { Estado da Assistência Social } \\
\text { - Colegiado Nacional de Gestores } \\
\text { Municipais da Assistência Social }\end{array}$ \\
\hline \multirow{8}{*}{ 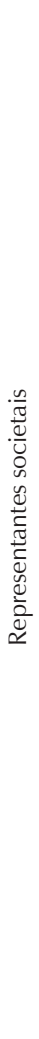 } & \multirow[t]{2}{*}{$\begin{array}{l}\text { Prestadores } \\
\text { privados de } \\
\text { serviços de as- } \\
\text { sistência social }\end{array}$} & $\begin{array}{l}\text { Jan./Mai. } 2010 \\
\text { • Federação Brasileira das Associa- } \\
\text { ções Cristãs de Moços }\end{array}$ & $\begin{array}{l}\text { Jun./Dez. } 2010 \\
\text { - União Social Camiliana } \\
\text { • União Brasileira de Educação e } \\
\text { Ensino }\end{array}$ \\
\hline & & & - Federação Nacional dos Psicólogos \\
\hline & $\begin{array}{l}\text { Profissionais e } \\
\text { trabalhadores } \\
\text { de assistência } \\
\text { social }\end{array}$ & $\begin{array}{l}\qquad \text { Jan./Mai. } 2010 \\
\text { - Federação Nacional dos Assisten- } \\
\text { tes Sociais } \\
\text { - Federação Nacional dos Empre- } \\
\text { gados em Instituições Beneficentes, } \\
\text { Religiosas e Filantrópicas }\end{array}$ & $\begin{array}{l}\qquad \text { Jun./Dez. } 2010 \\
\text { • Confederação Nacional dos } \\
\text { Trabalhadores em Seguridade Social } \\
\text { da CUT }\end{array}$ \\
\hline & $\begin{array}{l}\text { Trabalhadores } \\
\text { (não assistência } \\
\text { social) }\end{array}$ & & $\begin{array}{l}\text { Jun./Dez. } 2010 \\
\text { - Central dos Trabalhadores e Traba- } \\
\text { Ihadoras do Brasil }\end{array}$ \\
\hline & \multirow[t]{2}{*}{$\begin{array}{c}\text { Associações } \\
\text { de pessoas em } \\
\text { situação de } \\
\text { vulnerabilidade } \\
\text { social }\end{array}$} & & $\begin{array}{l}\text { Jun./Dez. } 2010 \\
\text { • Movimento Nacional de Popula- } \\
\text { ção de Rua }\end{array}$ \\
\hline & & & $\begin{array}{l}\text { - Federação Nacional das Associa- } \\
\text { ções para Valorização das Pessoas } \\
\text { com Deficiência }\end{array}$ \\
\hline & $\begin{array}{l}\text { Entidades de } \\
\text { pessoas com } \\
\text { patologias ou } \\
\text { deficiências }\end{array}$ & $\begin{array}{l}\text { Jan./Mai. } 2010 \\
\text { • União Brasileira de Cegos (UBC) } \\
\text { - Federação Nacional das Apaes }\end{array}$ & $\begin{array}{c}\text { Jun./Dez. } 2010 \\
\text { • Associação Brasileira de Autismo }\end{array}$ \\
\hline & Igrejas & $\begin{array}{l}\text { Jan./Mai. } 2010 \\
\text { - Associação da Igreja Metodista } \\
\text { - Conferência Nacional dos Bispos } \\
\text { do Brasil }\end{array}$ & $\begin{array}{c}\text { Jun./Dez. } 2010 \\
\text { • Federação Espírita Brasileira }\end{array}$ \\
\hline
\end{tabular}

Fonte: Brasil, 2008; 2010c. 
Em 2010, a maioria das questões debatidas pelo plenário foi apresentada pelos gestores federais ou integrou-se à pauta, porque o governo federal havia tomado medidas impactantes sobre o funcionamento da área e do próprio Conselho. Todos os assuntos relacionados à política nacional de assistência social chegaram à agenda do fórum dessa forma (Brasil, 2010b).

Uma vez que um tema entrasse na pauta, passava-se ao processo de análise que precedia a tomada de decisão pelo plenário. Na maior parte das vezes, acertos prévios iam sendo construídos entre os conseIheiros durante os trabalhos dos grupos e comissões, em seminários que envolviam participantes de órgão públicos e de entidades da sociedade civil, em encontros da Presidência Ampliada, que antecediam as plenárias, e também nos gabinetes ministeriais. Os conselheiros que lideravam o processo decisório do Conselho promoviam a elaboração de acordos. Quando o plenário deliberava e tomava decisões, em geral o fazia de forma consensual (A.S., entrevista, 10/10/2011; G.J., entrevista, 11/10/2011; P.L., entrevista, 06/09/2011).

Quem eram esses conselheiros que lideravam o processo decisório do Conselho? Atores estatais e sociais tinham participação expressiva em toda a reunião, porém, nos momentos cruciais para a decisão, aumentava a presença dos primeiros. O Gráfico 1 mostra que os representantes do governo federal eram os que mais se manifestavam em todas as fases das reuniões ${ }^{8}$. Porém, o tempo de suas intervenções crescia mais em relação às manifestações dos demais tipos de participantes durante o processo de análise de temas candentes da política de assistência social, e aumentava ainda mais na etapa decisiva dos debates em que se realizavam os encaminhamentos finais para as decisões a serem tomadas. Os não conselhei-

${ }^{8}$ As intervenções da Presidência do Conselho não foram consideradas nessa contabilização, pois dada sua proeminência na condução dos trabalhos, sua inclusão em um dos grupos poderia enviesar os resultados, aumentando artificialmente a contabilização do volume de intervenções do segmento a que a Presidência pertencesse. 
ros participavam mais do processo de análise. Isso, porque se tratavam de convidados especialistas em determinados assuntos que compareciam às reuniões para subsidiar com informações técnicas o processo de decisão dos conselheiros. No que tange aos atores sociais, dois tipos de participantes eram mais atuantes: os representantes de entidades de profissionais e trabalhadores de assistência social e de organizações religiosas. Se forem desconsideradas as intervenções dos não conselheiros, tendo em vista seu caráter principalmente informativo, os conselheiros provenientes de entidades de mercado prestadoras de serviços formavam o quarto grupo que mais se manifestava nas três fases das discussões.

Gráfico 1. Percentual de palavras por 10 tipos de participante segundo etapas das reuniões plenárias do CNAS- 2010

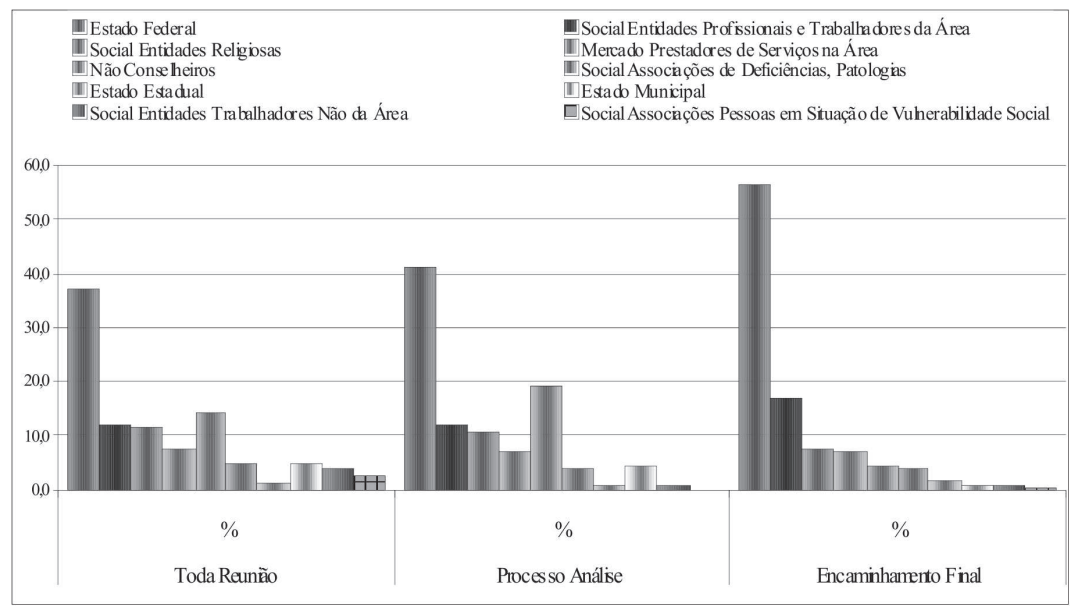

Fonte: Brasil, 2010b 
Sociologias, Porto Alegre, ano 17, no 38, jan/abr 2015, p. 122-154

À exceção dos representantes do governo federal, que tinham o maior volume de intervenções em todas as etapas das reuniões, a participação dos diferentes grupos de conselheiros variava de acordo com os temas em pauta. Os representantes de entidades de profissionais e trabalhadores da área, marcadamente psicólogos e assistentes sociais, foram os que mais interviram nas discussões que conduziram a edição, no ano seguinte, da Resolução NOB-RH/SUAS que estabeleceu as equipes de trabalhadores do SUAS (Brasil, 2011a). Sua participação durante as reuniões (4.433 palavras registradas em ata) foi superior, inclusive, à dos representantes do governo federal (1.105 palavras) (Brasil, 2010b). Na discussão da NOB/SUAS 2010 (Brasil, 2010c), que instituiu novos mecanismos para habilitação dos municípios em diferentes níveis de gestão e ampliou a regulação governamental sobre os serviços socioassistenciais, entre outras medidas de fortalecimento integração e da gestão federativa do sistema, os representantes de entidades de profissionais e trabalhadores da área foram superados em volume de intervenções apenas pelos os representantes da gestão federal (3.829 e 1.626 palavras respectivamente). Os conselheiros provenientes de entidades religiosas interviram mais quando o CNAS tratou da Lei 12.101 (Brasil, 2009), que retirou do fórum a responsabilidade pela certificação de benemerência. Apenas as manifestações de representantes do governo federal (12.990 palavras) superaram o volume de suas intervenções (2.100 palavras) durante as discussões sobre a regulamentação da Lei.

Existem duas características fundamentais da dinâmica de funcionamento do CNAS que facilitam a compreensão de como ele modificou o seu papel na área ao final da década de 2000. A primeira se refere à hegemonia exercida pelos representantes do governo federal no Conselho. Sua participação em todos os momentos das reuniões plenárias era constante, acentuando-se ainda mais nas fases de decisão. Com o acelerado crescimento da importância da política de assistência social, programas, 
Sociologias, Porto Alegre, ano 17, no 38, jan/abr 2015, p. 122-154

projetos e normas editadas pelos gestores federais necessariamente ingressavam na agenda do fórum. Entretanto, os dirigentes federais da área não se contentaram em estabelecer a agenda do CNAS. Houve uma ação deliberada no sentido de dirigir os trabalhos do Conselho e de, inclusive, alterar seu papel institucional.

A segunda dimensão está relacionada às alianças e conflitos entre grupos de conselheiros que caracterizaram a dinâmica política (politics), tanto no interior do fórum, como na área de assistência social, no período. Além dos representantes da gestão federal, outros dois grupos de participantes eram muito ativos no Conselho: os conselheiros provenientes de entidades de profissionais e de trabalhadores do setor e de entidades religiosas em aliança com os prestadores de serviços de assistência social. A aliança era fundamentada na estreita ligação entre prestadores de serviços e entidades religiosas. A composição do plenário do CNAS em 2010 mostra isso: os três representantes de entidades prestadoras de serviço de assistência eram oriundos de organizações religiosas cristãs (Federação Brasileira das Associações Cristãs de Moços; União Social Camiliana, União Brasileira de Educação e Ensino, marista) (ver Quadro 1). Os representantes de entidades profissionais e de trabalhadores do setor defendiam seus interesses corporativos, como ocorreu na discussão da Resolução NOB-RH/SUAS. Porém, os conselheiros mais atuantes desse grupo identificavam-se com o projeto governamental de construção do SUAS. Eles também integravam a policy community reformista (G.J., entrevista, 11/10/2011).

As tensões nos debates do Conselho ocorriam principalmente entre os representantes da gestão federal e de entidades religiosas em aliança com os prestadores de serviços. Os primeiros defendiam o aumento do papel do Estado na organização e regulação do sistema em consolidação. Os dois últimos representavam os interesses de prestadores de serviços de assistência social, e posicionavam-se contra o que viam, por vezes, como excesso de intervenção governamental. 
Sociologias, Porto Alegre, ano 17, no 38, jan/abr 2015, p. 122-154

Apesar das tensões que a estruturação do SUAS provocou entre a policy community que a promovia e as entidades religiosas e de prestadores de serviços, os gestores federais integrantes dessa community impuseram seu projeto reformista na área. A área tradicionalmente apresentava baixa normatização legal e administrativa e os gestores municipais pouco interferiam sobre o modo como a provisão de serviços era realizada por provedores privados ou filantrópicos. As resistências às mudanças partiam tanto dessas entidades, desacostumadas com os novos mecanismos públicos de controle sobre suas ações, quanto de gestores municipais habituados a práticas clientelistas e ao 'primeiro-damismo', compelidos não apenas a assumir novas responsabilidades como também a organizar a oferta de bens e serviços sociais de acordo com critérios técnicos (F.L., entrevista, 14/03/2012; G.J., entrevista, 11/10/2011). O sucesso no esforço reformista deveu-se a vários fatores, entretanto, um elemento decisivo foi a ação dos integrantes dessa community, que utilizaram uma janela de oportunidades aberta com a ascensão de Patrus Ananias, ao comando do MDS, para acelerar a consolidação do SUAS de acordo com os princípios de universalidade do direito a assistência social, descentralização administrativa, unificação e hierarquização da rede assistencial, participação social e controle público da oferta de bens e serviços sociais. A modificação do papel institucional do CNAS se inseria nesse processo.

\section{Policy community defensora da assistência social como} direito e a mudança no papel institucional do Conselho Nacional de Assistência Social (CNAS)

O governo Lula, iniciado em 2002, colocara no centro da agenda governamental a questão das desigualdades sociais e da pobreza no país. Entretanto, somente quando Patrus Ananias assume o comando do MDS, 
em 2004, é que integrantes da policy community defensora da assistência social como direito viram suas propostas de fato assumidas como política de governo ao mesmo tempo em que ocuparam cargos no governo federal (A.S., entrevista, 10/10/2011; F.L., entrevista, 14/03/2012). Aberta a janela oportunidades, estabelecido o problema na agenda governamental, as alternativas de solução escolhidas foram aquelas que eram mais compatíveis com a visão da policy community reformista. Por isso, a partir de 2004, acelerou-se o processo de constituição do SUAS iniciado nos anos 1990. Em 2004 e 2005, respectivamente, o MDS lançou o Plano Nacional de Assistência Social (Brasil, 2004) e a NOB-SUAS (Brasil, 2005), que instituíram o SUAS e estabeleceram suas regras básicas de funcionamento. Observe-se que as duas medidas foram publicadas como Resoluções do Conselho Nacional de Assistência Social e não como Portarias Ministeriais. Esse fato, por si só, se constituiu em uma indicação do papel central que CNAS desempenhou na área, no período.

Os novos decisores que impulsionavam a instituição do SUAS no país viam o Conselho como um centro irradiador da normatização que organizava o sistema em formação (A.S., entrevista de 10/10/2011). Em diversos municípios do país, não havia órgãos governamentais que tratassem com exclusividade da política de assistência social ou gestores municipais sensibilizados a considerar a assistência social como direito dos cidadãos (G.J., entrevista de 11/10/2011). O CNAS ocupava o topo de uma cadeia de fóruns participativos estaduais e municipais, capaz de levar as decisões do fórum aos estados e municípios. Além disso, como a capacidade administrativa da área era pequena e o poder do CNAS no sistema muito grande, 'administrar' por meio de Resoluções do Conselho foi considerado como o caminho mais curto e rápido para viabilizar a implementação das diretrizes que passavam a organizar o SUAS. Uma das principais lideranças no CNAS, representante do governo federal, explica no trecho de entrevista a seguir a estratégia adotada. 
Sociologias, Porto Alegre, ano 17, no 38, jan/abr 2015, p. 122-154

Nós precisávamos fazer mudanças rápidas no governo federal, mudanças na área, implantar o Sistema Único de Assistência Social, mudar a normatização da área. Então, a gente sabia que se fosse pelo trâmite burocrático de portarias, decretos e legislação, ia demorar mais. Então, a gente foi por Resoluções do Conselho Nacional. (...) Então, a gente construiu todo um projeto e fomos implantando o SUAS por Resoluções do Conselho Nacional, mesmo antes de transformá-lo [o SUAS] em lei (A.S., entrevista de 10/10/2011).

Aprovar propostas era relativamente fácil, tendo em vista que os gestores federais e seus aliados eram maioria no fórum. Mas, para que as resoluções fossem consideradas legítimas, era necessário exercer a arte da persuasão (Goodin et al., 2006) sobre os conselheiros. Desse modo, haveria o compromisso de implementar as decisões tomadas em suas organizações. Era essencial um trabalho de convencimento, inclusive daqueles que se opunham inicialmente às propostas. Isso era buscado ativamente pelos gestores federais, como é ilustrado no seguinte trecho de entrevista:

Normalmente, quando o Conselho chega a elaborar uma Resolução, já tem bastante consenso. Todo mundo sabe que vai ser aprovado. (...) Nunca é uma decisão mais inteligente ter que decidir questões muito importantes pelo voto. Quando chega nisso, é sinal de que o debate foi pouco, é preciso debater mais um pouco. Não que os interesses não sejam diferentes. Eles são diferentes, mas é preciso que os conselheiros esgotem a capacidade de criar consensos (A.S., entrevista, 10/10/2011).

Os consensos construídos no interior do CNAS estavam assentados sobre uma base de apoios de indivíduos, grupos e organizações que, independentemente de estarem nos governos, em associações profissionais, sindicatos ou mesmos em organizações prestadoras de serviços, compartilhavam a noção de que a assistência social era um direito dos cidadãos. Concepções liberais que questionavam essa noção não tinham expressão no Conselho (G.J., entrevista, 11/10/2011; Brasil, 2010b). A 
Sociologias, Porto Alegre, ano 17, no 38, jan/abr 2015, p. 122-154

defesa da assistência como caridade destinada a merecedores realizava-se fora do Conselho e do centro decisório do governo federal, em lugares como o Congresso Nacional, em algumas prefeituras e governos estaduais e em espaços generosos da mídia nacional (A.S., entrevista, 10/10/2011; B.L., entrevista, 19/06/2010; G.J., entrevista, 11/10/2011; P.L., entrevista, 06/09/2011). No interior do fórum, as divergências diziam respeito ao grau de regulação que governo deveria exercer sobre os prestadores de serviços filantrópicos ou privados.

As entidades religiosas e de prestadores de serviços concordavam que a assistência social é um direito dos cidadãos, bem como com a expansão da provisão dos serviços assistenciais financiada com recursos públicos. Contrapunham-se, no entanto, à ampliação do controle governamental - especialmente federal e municipal - sobre a organização e provisão de serviços, resultante das normas legais e administrativas editadas depois de 2004. Segundo eles, ao governo federal cabia formular políticas e coordenar o sistema, mas argumentavam que a complementaridade dos prestadores de serviços não governamentais na execução das políticas sociais, estabelecida pela a legislação, não estava sendo devidamente respeitada pelos governantes (P.L., entrevista, 06/09/2011).

O processo de transformação do Conselho em fonte de produção de normas para acelerar a estruturação nacional do SUAS e para aumentar o controle estatal sobre o sistema intensificou-se ainda mais quando a policy community reformista divisou uma nova janela de oportunidades favorável à neutralização das resistências das entidades religiosas e de prestadores de serviços: a Operação Fariseu. Promovida pela Polícia Federal, em 2008, a Operação comprovou que mantenedoras de redes de serviços de hospitalares, educacionais e de assistência social subornavam integrantes do CNAS, para facilitar a obtenção de certificados de benemerência, necessários para a obtenção de isenções fiscais. A fraude, 
que ocupou largos espaços na mídia nacional, teria resultado em mais de quatro bilhões de desvios de recursos do fisco brasileiro (ESTADÃO, 2008, 13/03/08). A Operação enfraqueceu a posição política e a imagem pública das organizações religiosas e de prestadores de serviços sociais (A.S., entrevista, 10/10/2011).

A manutenção do CNAS como 'cartório' para concessão de certificados de benemerência era vista pelos gestores federais como uma das razões para as dificuldades em efetivar a legislação complementar à carta constitucional que regulamentava a filantropia (Brasil, 1991; 1993; 1993b; 1998; 1999; 2002; 2003; entre outros), especialmente no que tange ao controle público sobre o cumprimento das exigências legais para a concessão e manutenção dos certificados. Com a fragilização política dos principais opositores à mudança, foi possível, após um intenso e conflitivo debate na área (A.S., entrevista, 10/10/2011) aprovar, em 2009, a Lei Federal no 12.101 (Brasil, 2009), que transferiu do CNAS para as burocracias do MDS, e dos Ministérios da Saúde e da Educação, a prerrogativa de conceder certificação de benemerência nas áreas de assistência social, saúde e educação, respectivamente. A Lei ainda estabeleceu os três Ministérios como responsáveis pela fiscalização do cumprimento das exigências legais para a manutenção do certificado.

As entidades religiosas e de prestadores de serviços aceitaram que o Conselho deixasse de ser o órgão certificador e que os critérios de concessão e manutenção dos certificados se tornassem mais rígidos, porém não se conformaram com transferência para os Ministérios da Saúde e da Educação da prerrogativa de avaliar a benemerência de prestadores de serviços de saúde e de educação. Insistiam que independentemente da área em que o serviço fosse prestado - saúde, educação ou assistência social - a natureza de entidade prestadora, não lucrativa, é que deveria se constituir em critério básico para caracterizar uma entidade como be- 
neficente de assistência social. Para eles o processo de certificação não deveria sair da área (P.L, entrevista, 06/09/2011), na qual, historicamente, seu predomínio fora maior (A.S., entrevista, 10/10/2011; G.J., entrevista, 11/10/2011). Como afirma um conselheiro representante dos gestores federais no CNAS,

O governo conseguiu, com sua proposta, deixar claro que escola é área da educação. Pode parecer ridículo um negócio desses, quer dizer, deixar claro que hospital é ligado à área da saúde. (...) É uma das partes que mais incomoda os setores mais conservadores no Conselho Nacional, e não só os conservadores. (...) Esse assunto vive querendo voltar à tona (A.S., entrevista, 10/10/2011).

Mesmo com a oposição do ator societal mais poderoso na área, a policy community que defendia a assistência social como direito mudou o papel institucional do Conselho. Sua transformação em uma fonte de criação e difusão de normas para a organização e gestão do sistema se expressa no conjunto de decisões que tomou em 2010, logo após, portanto, à aprovação da Lei 12.101. As principais Resoluções emanadas do Conselho trataram: do estabelecimento de parâmetros para certificação de entidades beneficentes de assistência social; da NOB/SUAS 2010, que instituiu novos mecanismos para habilitação dos municípios em diferentes níveis de gestão e ampliou a regulação governamental sobre os prestadores de serviços, entre outras medidas de fortalecimento integração e da gestão federativa do sistema; da NOB-RH/SUAS, que normatizou as equipes de trabalhadores do SUAS; da caracterização de entidades de assistência social, de assessoramento e de defesa e garantia de direitos; da caracterização dos benefícios de eventuais assistenciais; do controle social do Programa Bolsa Família; e definição das competências do Fundo Nacional do Idoso (Brasil, 2010b). A importância dessas decisões e o seu indiscutível impacto na consolidação do SUAS - como um sistema descentralizado, hierarquizado, coordenado 
Sociologias, Porto Alegre, ano 17, no 38, jan/abr 2015, p. 122-154

pelo governo federal, com mecanismos de gestão federativa e participativa, que oferece serviços e bens sociais por meio de profissionais e trabalhadores habilitados aos cidadãos em situação de necessidade - demonstra que a policy community reformista teve sucesso em sua estratégia de modificar o papel institucional do CNAS. O Conselho, assim, participou de forma decisiva no processo de estruturação do SUAS de acordo com a visão de sistema que a community defendia.

\section{Considerações finais}

A constituição de uma política nacional de assistência social no país e a transformação do papel do CNAS resultaram, em parte, da ação estratégica de uma policy community que defendia, desde os anos 1980, a assistência social como um direito dos cidadãos. Membros dessa community aproveitaram sucessivas janelas de oportunidades para apresentar aos decisores políticos propostas de solução para os problemas da extremada desigualdade social e pobreza, colocados no centro da agenda política e governamental durante o Governo Lula, iniciado em 2002. Patrus Ananias, ao assumir o MDS em 2004, mostrou-se particularmente sensível a aceitar suas proposições como soluções para esses problemas, além nomear integrantes dessa community para cargos de direção no Ministério. A partir de 2004, o nível federal de gestão da área editou normas legais e administrativas que criaram e organizaram o SUAS de acordo com os princípios de descentralização, controle do setor público sobre o modo de provisão de bens e serviços e participação societal, viabilizando a implementação do sistema na federação brasileira.

Os conflitos que ocorreram no interior do fórum refletiam divergências principalmente ao nível de controle governamental sobre o sistema. Contrapunham-se representantes do governo federal, frequentemente em 
Sociologias, Porto Alegre, ano 17, no 38, jan/abr 2015, p. 122-154

aliança com conselheiros oriundos de entidades de profissionais e trabaIhadores da área, e de entidades religiosas e de prestadores de serviços. Os primeiros queriam ampliar o poder estatal sobre o sistema em formação e os segundos manter a autonomia de ação que historicamente detiveram. Uma nova janela de oportunidades configurou-se para a policy community reformista quando a Operação Fariseu, em 2008, expôs publicamente a existência de relações ilícitas entre certos conselheiros e entidades que recebiam certificação como beneficentes de assistência social e, portanto, vultosas isenções fiscais. A Lei 12.101, de novembro de 2009, retirou do fórum a prerrogativa de certificar e controlar as atividades de entidades 'beneficentes' - com direito a isenções fiscais - transferindo-a as burocracias governamentais das áreas de assistência social, saúde e educação.

No ano seguinte à edição da Lei, o Conselho não apenas refletiu sobre suas novas funções como colaborou de forma decisiva para o estabelecimento de um conjunto de regras relativas à organização do SUAS no país. Suas resoluções trataram das categorias profissionais que deveriam integrar as equipes de assistência social; da tipificação de benefícios e serviços assistenciais; da caracterização de entidades de assistência social, de assessoramento e de defesa e garantia de direitos e da definição de competências exclusivas da área, entre outros temas similares. As resoluções do CNAS, ao lado das Normas Operacionais Básicas da Assistência Social compuseram um conjunto normativo essencial para a institucionalização do SUAS na federação brasileira.

O CNAS, uma organização intermediária neocorporativa criada pela Lei Orgânica da Assistência Social (Brasil, 1993), vem exercendo forte influência no sentido de estabelecer a intermediação de interesses entre os diversos atores societais. Mas o mais importante é que seus participantes, e também aqueles que integravam conselhos estaduais e municipais tornaram-se corresponsáveis pelo cumprimento de decisões do CNAS 
junto a suas organizações e nos municípios e estados em que atuavam, comprometendo-se assim com a implementação das políticas definidas no nível federal de gestão. Espera-se que o CNAS continue agindo como veículo poderoso de consolidação de um sistema de assistência social que colabore para inclusão social de milhões de brasileiros.

Soraya Vargas Cortes - Doutora em Social Policy and Administration pela London School of Economics and Political Science, em 1995. Atualmente é professora do Departamento e Programa de Pós-Graduação em Sociologia da Universidade Federal do Rio Grande do Sul, Pesquisadora do CNPQ, é coordenadora adjunta do Comitê de Avaliação da Pós-Graduação da Capes, na Sub-Área de Sociologia e é Presidente da Sociedade Brasileira de Sociologia.

$\sum$ vargas.cortes@ufrgs.br

\section{Referências}

1. ALEXANDER, J. C.. Theoretical Logic in Sociology. Positivism, Presuppositions, and Current Controversies (v. 1). Berkeley: University of California Press, 1982.

2. A.S. Entrevista realizada em 10 de outubro de 2011. Brasília. Transcrita. ArquivOS GPPS/UFRGS.

3. ALCOCK, P.. The subject of social policy. In: P. ALCOCK, A. ERSKINE and M. MAY (eds.). The Student's Companion to Social Policy. Blackwell/Social Policy Association, Oxford, 2003.

4. B.L. Entrevista realizada em 19 de junho de 2010. Porto Alegre. Transcrita. Arquivos GPPS/UFRGS.

5. BRASIL. Constituição da República Federativa do Brasil de 05 de Outubro de 1988. Assembleia Nacional Constituinte.

6. BRASIL. Lei 8.212 de 24 de Julho de 1991 - Dispõe sobre a organização da Seguridade Social, institui Plano de Custeio, e dá outras providências.

7. BRASIL. Lei 8.742 de 7 de Dezembro de 1993 - Dispõe sobre a organização da assistência social e dá outras providências. Congresso Nacional.

8. BRASIL. Decreto 752, de 16 de fevereiro de 1993a. Dispõe sobre a concessão do Certificado de Entidade de Fins Filantrópicos, a que se refere o art. 55, inciso II, da Lei nº 8.212, de 24 de julho de 1991, e dá outras providências. 
9. BRASIL. Decreto 2.536, de 6 de abril de 1998. Dispõe sobre a concessão do Certificado de Entidade de Fins Filantrópicos a que se refere o inciso IV do art. 18 da Lei no 8.742, de 7 de dezembro de 1993, e dá outras providência.

10. BRASIL. Lei 9.790, de 23 de março de 1999. Dispõe sobre a qualificação de pessoas jurídicas de direito privado, sem fins lucrativos, como Organizações da Sociedade Civil de Interesse Público, institui e disciplina o Termo de Parceria, e dá outras providências.

11. BRASIL. Decreto 4.588, de 7 de fevereiro de 2003. Revoga o Decreto no 4.481 de 22 de novembro de 2002, que dispõe sobre os critérios para definição dos hospitais estratégicos, no âmbito do Sistema Único de Saúde.

12. BRASIL. Decreto 4.327, de 8 de agosto de 2002. Aprova critérios para concessão do certificado de filantropia para os hospitais.

13. BRASIL. Ministério do Desenvolvimento Social e Combate à Fome. Plano Nacional de Assistência Social. Brasília: MDS, novembro, 2004.

14. BRASIL. Ministério do Desenvolvimento Social e Combate à Fome. Norma Operacional Básica - NOB/SUAS - Construindo as bases para a implantação do Sistema Único de Assistência Social. Brasília: MDS, julho 2005.

15. BRASIL. Ministério do Desenvolvimento Social e Combate à Fome. Financiamento da Assistência Social no Brasil. Caderno SUAS, ano 2, n. 2. Brasília, 2007.

16. BRASIL. Resolução N. 53, de 31 de julho de 2008. Aprova o novo Regimento Interno do Conselho Nacional de Assistência Social. Conselho Nacional de Assistência Social, 2008.

17. BRASIL. Lei № 12.101, de 27 de novembro de 2009. Dispõe sobre a certificação das entidades beneficentes de assistência social; regula os procedimentos de isenção de contribuições para a seguridade social; altera a Lei no 8.742, de 7 de dezembro de 1993; revoga dispositivos das Leis nos 8.212, de 24 de julho de 1991, 9.429, de 26 de dezembro de 1996, 9.732, de 11 de dezembro de 1998, 10.684, de 30 de maio de 2003, e da Medida Provisória no 2.187-13, de 24 de agosto de 2001; e dá outras providências. Congresso Nacional, 2009.

18. BRASIL. Resolução N. 70 de 17 de agosto de 2009. Altera o Regimento Interno, o Manual de Procedimentos e arquiva os processos com diligências não cumpridas pelas respectivas entidades. Conselho Nacional de Assistência Social, 2009a.

19. BRASIL. Secretaria Geral da Presidência da República. Secretaria Nacional de Articulação Social. Conselhos Nacionais. Brasília: Presidência da República, 2010.

20. BRASIL. Organograma. Conselho Nacional de Assistência Social, 2010a. Disponível em: http://www.mds.gov.br/cnas/menu_superior/organograma/organograma-cnas.jpg/view. Acesso em 10/01/2011. 
21. BRASIL. Atas de reunião. Conselho Nacional de Assistência Social, 2010b. Disponível em: http://www.mds.gov.br/cnas/reunioes-do-cnas/reunioes-ordinarias/atas/ Atas\%20 de\% 202010/atas-de-2010/. Acesso em jan-jul de 2011.

22. BRASIL. Ata da reunião № 178. Conselho Nacional de Assistência Social, 2010c. Disponível em: http://www.mds.gov.br/cnas/reunioes-do-cnas/reunioesordinarias/atas/ Atas\%20de\%202010/atas-de-2010/. Acesso em março de 2011.

23. BRASIL. NOB/SUAS 2010: Aprimoramento da Gestão e Qualificação dos Serviços Socioassistenciais. Ministério do Desenvolvimento Social e Combate à Fome, Brasília, 2010d.

24. BRASIL. Resolução № 16, de 5 de maio de 2010. Define os parâmetros nacionais para a inscrição das entidades e organizações de assistência social, bem como dos serviços, programas, projetos e benefícios socioassistenciais nos Conselhos de Assistência Social dos Municípios e do Distrito Federal. Conselho Nacional de Assistência Social, 2010e.

25. BRASIL. Resolução N.o 38 de 11 de novembro de 2010. Constitui Grupo de Trabalho para discutir parâmetros de caracterização de entidades de assessoramento e de defesa e garantia de direitos. Conselho Nacional de Assistência Social, $2010 f$.

26. BRASIL. Resolução № 17, de 20 de junho de 2011. Ratificar a equipe de referência definida pela Norma Operacional Básica de Recursos Humanos do Sistema Único de Assistência Social - NOB-RH/SUAS e Reconhecer as categorias profissionais de nível superior para atender as especificidades dos serviços socioassistenciais e das funções essenciais de gestão do Sistema Único de Assistência Social - SUAS. Conselho Nacional de Assistência Social, 2011.

27. BRASIL. Presidência da República, 2012. Disponível em: http://www.biblioteca. presidencia.gov.br/ministerios. Acesso em 15/03/2012

28. CASTRO, Jorge et al. Gasto Social Federal: prioridade macroeconômica no período 1995-2010. Brasília: Ipea, Nota técnica no 9, 2012.

29. COHEN, J. L. Sociedade civil e globalização: repensando categorias. Dados - Revista de Ciências Sociais, 46(3), 2003, p. 419-459.

30. CÓRDOVA, E.. From corporatism to liberalisation: the new directions of the Brazilian system of industrial relations. Labour and Society 13 (3), 1989, p. 251269.

31. CÔRTES, S. M. V. Brazil's National Council for Social Assistance and the policy community supporting social assistance as a right. In: Vaitsman, Jeni; Ribeiro, José M.; Lobato, Lenaura. (Org.). Policy Analysis in Brazil. 1ed.Bristol, UK: Polity Press, 2013, p. 135-148. 
32. CÔRTES, S. M. V. ; GUGLIANO, A. A.. Entre neocorporativos e deliberativos: uma interpretação sobre os paradigmas de análise dos fóruns participativos no Brasil. Sociologias 24, Porto Alegre, 2010, p. 44-75.

33. DINIZ, E.. Neoliberalismo e corporativismo: as duas faces do capitalismo industrial brasileiro. Revista Brasileira de Ciências Sociais. 20 (7), p. 31-46, 1992.

34. DUNLEAVY, P.. Professions and policy change: notes towards a model of ideological corporatism. Public Administration Bulletin, vol. 36, 1981, p. 3-16.

35. ESTADÃO. Prejuízo com esquema de falsas filantrópicas chega a $\mathbf{4}$ bilhões. 13/03/08

36. F.L. Entrevista realizada em 14 de março de 2012. Brasília. Transcrita. Arquivos GPPS/UFRGS.

37. FIGUEIREDO, A.C., LIMONGI, F. e VALENTE, A.L.. Governabilidade e concentração de poder institucional: o governo FHC. Tempo Social - revista de sociologia da USP. Out, 11 (2), 1999, p. 49-62.

38. G.J. Entrevista realizada em 11 de outubro de 2011. Brasília. Transcrita. Arquivos GPPS/UFRGS.

39. GOODIN, R. E.; REIN, M.; MORAN, M.(Orgs.). The Oxford Handbook of Public Policy. Oxford: Oxford University Press, 2006.

40. HECLO, H.. Issue network and the executive establishment. In: KING, A. (Ed.) The New American Political System. Washington, D.C.: American Enterprise Institute for Public Policy Research, 1978.

41. IBGE. Munic 2009. Disponível em: http://www.ibge.gov.br/home/presiden$\mathrm{cia} /$ noticias/noticia_visualiza.php?id_noticia $=1612 \&$ id_pagina $=1$. Acesso em 02/12/2010.

42. INGRAM, H; A.L. SCHNEIDER; e P.DELEON. Social construction and polily design. In: SABATIER, Paul A.. (Org.). Theories of the policy process. Cambridge, MA: Westview Press, p. 93-126, 2007.

43. JORDAN, G. \& RICHARDSON, J. J.. Governing Under Pressure. Oxford: Martin Robertson, 1979.

44. KINGDON, J. W.. Agendas, alternatives and public policies. New York: Harper Collins, 1995.

45. LAMPING, A. J.; RAAB, J.; KENIS, P. Patients in the lead, the public in need: An evaluative study of the system of intermediate organizations in Dutch health care. Rijksoverheid [On line], 2010. Disponível em: http://www.rijksoverheid.nl/ documenten-en-publicaties/rapporten/2011/01/19/patients-in-the-lead-the-public-in-need.html. Acesso em 14/03/2011. 
Sociologias, Porto Alegre, ano 17, o 38, jan/abr 2015, p. 122-154

46. LARSONS, M. S.. The Rise of Professionalism. Berkeley: University of California Press, 1977.

47. LEHMAN, E.W.. The theory of the State versus the state of theory. Amer. Sociol. Rev. 2010, 53 (6): 807-823.

48. MENEZES, F.C.. O Serviço Social e a "responsabilidade social das empresas": o debate da categoria profissional na Revista Serviço Social \& Sociedade e nos CBAS. Revista Serviço Social \& Sociedade, 103, p. 503-531, 2010.

49. MISHRA, R.. The Welfare State in Crisis. Brighton: Wheatsheaf Books, 1984.

50. NOGUEIRA, A.J.F.M.. Emergência e crise do Novo Sindicalismo no setor público brasileiro. In: I.J. Rodrigues (Org.). O novo sindicalismo: vinte anos depois. Petrópolis: Vozes, 1999.

51. O'DONNELL, G.. Reflections on the Patterns of Change in the BureaucraticAuthoritarian State. Latin American Research Review, 13(1), 1978, p. 102-131.

52. P.L. Entrevista realizada em 6 de setembro de 2011. Porto Alegre. Transcrita. Arquivos GPPS/UFRGS.

53. PAGE, E. C.. The origens of policy. In GOODIN, R. E.; REIN, M.; MORAN, M.(Orgs.). The Oxford Handbook of Public Policy. Oxford: Oxford University Press, p. 207-227, 2006.

54. PICHLER, W.A.. Changing industrial relations in Brazil: developments in collective bargaining in Rio Grande do Sul, 1978 - 1991. PhD Thesis - University of London, London School of Economics and Political Science, 2005.

55. RAICHELIS, R.. Esfera pública e conselhos de assistência social. Caminhos da construção democrática. São Paulo: Cortez, 2000.

56. RHODES, R. A. W.. The National World of Local Government. Oxford: Allen and Unwin, 1986.

57. RODRIGUES, L.M.. Partidos e Sindicatos. São Paulo: Ática, 1990.

58. SANTOS, M. H. C. Which Democracy? A Conceptual View from the Developing Countries Perspectives. Dados [online], vol.44, no.4, 2001, p.729-771. Disponível em: <http://www.scielo.br/scielo.php?script=sci_arttext\&pid=S0011$52582001000400003 \& \operatorname{lng}=$ en\&nrm $=$ iso $>$.

59. SCHMITTER, P.C.. Interest conflict and political change in Brazil. Stanford: Stanford University Press, 1971.

60. SMITH, M. M.. From policy community to issue network: salmonella in eggs and the new politics of food. Public Administration, 69 (Summer), 1991, p. 235255. 
Sociologias, Porto Alegre, ano 17, no 38, jan/abr 2015, p. 122-154

61. STEPAN, A.. State Power and the Strength of Civil Society in the Southern Cone of Latin America. In: EVANS, P.B.; RUESCHEMEYER, D.; and SKOCPOL, T. (Eds.). Bringing the State Back. Cambridge: Cambridge University Press, 1985, p. 39-82.

62. STREECK, W \& KENWORTHY, L.. Theories and Practices of Neocorporatism. In: JANOSKI, T. (Org.) The Handbook of Political Sociology. Cambridge: Cambridge Univ. Press, 2005, p. 441-460.

63. TRUE, J. L.; JONES, B. D. \& BAUMGARTNER, F. R.. Punctuated-equilibrium theory: explaining stability and change in public policy making. In: SABATIER, P. A. (Ed.) Theories of the Policy Process. Boulder: Westview Press, 2007.

64. VAITSMAN, J.; ANDRADE, G.R.B. \& FARIAS, L.O.. Proteção social no Brasil: o que mudou na assistência social após a Constituição de 1988. Ciência \& Saúde Coletiva, 14(3), 2009, p.731-741.

65. WILLIAMSON, P. J.. Corporatism in Perspective. London: Sage, 1989.

Recebido em: 04/09/2014

Aceite final: 08/11/2014 